\title{
Aqui tudo é crónica, exceto o que não é: as crónicas e o legado de António Lobo Antunes
}

\author{
ANDRÉ CORRÊA DE SÁ \\ University of California, Santa Barbara
}

\begin{abstract}
While urging readers to recognize the importance of his novels in the history of literature, António Lobo Antunes constantly undervalues his chronicles. For him, the value of these shorter works rests on the fact that they may help readers to cope with his dense and complex novels. In this essay, I argue that we may use an ecological perspective to reconfigure, in alternative terms, Lobo Antunes's generic hierarchy. In particular, I maintain that one can better articulate what Timothy Morton calls "ecological thought" through the form of the chronicle. Contrary to Lobo Antunes's taxonomy of his own work and, above all, contrary to his belief in the novel's enduring power, I claim that his chronicles - due to their environmental significance - represent his greatest contribution to Portuguese letters.
\end{abstract}

Keywords: Chronicle, Portuguese novel, genre, ecological thought, Timothy Morton

Desde que as crónicas que publicava na imprensa e ia reunindo em volume começaram a empolgar mais os leitores do que os seus romances, António Lobo Antunes, de modo polémico, veio logo alertar-nos de que esses textos "literariamente não valem um traque." "Nos livros," explica-nos o autor num momento de auto-análise, "eu jogo a vida, nas crónicas não jogo nada" (Filipe 113). Mais do que uma provocação ao leitor desavisado, este desabafo alude tanto ao tópico maior dos seus livros como ao programa de treinamento que Lobo Antunes tem desenvolvido desde que, ainda criança, se decidiu pela carreira nas 
letras. Lobo Antunes imagina-se a si próprio como um homem constantemente invadido pela linguagem do Outro e ao livro como a caixa de ressonância onde se produz o encontro entre as almas invasoras e a mão semi-desperta que copia para o papel o que lhe dizem.

Como se sabe, muitas crónicas descrevem em detalhe os seus processos de criação. A variante mais exemplar de que dispomos ainda é a que está esboçada na célebre crónica "Receita para me lerem" (SLC 113-16), ${ }^{1}$ em gesto lapidar de auto-interpretação, e configura o "livro" como o desejo de um emparelhamento absoluto entre a "escrita" e o "mundo." Para Lobo Antunes, o livro deve tornarse a forma que nos expõe a todas as formas do mundo. Importa, por isso, que o leitor se concentre no que nele está latente. Implícito no argumento de "Receita para me lerem" está também o facto de que esse emparelhamento perfeito é o que nos permite diferenciar o romance da crónica, e a sugestão de que o que valida os seus romances e os assemelha entre si-e ao mesmo tempo os diferencia das crónicas - é a combinação da capacidade de transitar do físico para o metafórico com o sentido universal e intemporal que assinala a Autêntica Obra de Arte. Leiase Autêntica Obra de Arte, para dar um exemplo empírico ao melhor estilo antuniano, como o objecto que resulta do desejo de querer introduzir a Vida Toda entre as páginas de um livro. O livro - que umas vezes quer dizer romance, outras não, embora eu aqui as use como sinónimos —é, portanto, o corolário da aventura de erguer com as próprias mãos uma "catedral de palavras" (QUINLC 293). O leitor de Lobo Antunes está já suficientemente familiarizado com esta visão heróica do ofício do escritor. Ainda assim, parece-me útil resumir os momentos decisivos dessa cosmogonia particular.

Nas primeiras entrevistas, Lobo Antunes ainda se apresentava como um psiquiatra que escrevia romances nas poucas horas livres que lhe sobravam do quotidiano de psicoterapeuta célebre, cumprindo planos narrativos detalhados e aproveitando a autobiografia e as histórias de família, a contra-luz, para criar as personagens e o enredo dos livros. Porém, à medida que se tornou um escritor aclamado por adeptos fervorosos, Lobo Antunes ficou exposto a uma série de riscos ocupacionais. Como resultado dessa exposição, o autor como que foi perdendo a autoridade central sobre os livros. Os blocos de receita onde escreve

\footnotetext{
${ }^{1}$ Ao referir-me aos livros de António Lobo Antunes, utilizo as seguintes siglas: SLC (Segundo livro de crónicas), TLC (Terceiro livro de crónicas) e QUILC (Quinto livro de crónicas).
} 
as primeiras versões ainda são os mesmos blocos de prescrição hospitalar onde surgiram Memória de elefante e Os cus de Judas, e o tratamento terapêutico da realidade ainda é promovido em moldes semelhantes. Porém, nos últimos anos, ao mesmo tempo que começou a discorrer em várias crónicas e entrevistas a respeito das conotações atléticas do ofício de escrever romances, Lobo Antunes começou a insistir na ideia de que não se reconhece como autor dos livros que escreveu e mesmo na ideia de que a autoria dos livros que escreve nem sequer lhe pertence. Escreve ele, evocando o "estado próximo dos sonhos" que o domina durante a conceção do romance: "vêm não sei de onde, não sei como [...]. Deveriam editar-se sem autor na capa, porque desconheço quem o autor é." (TLC 145). Ao contrário do que se poderia pensar, esta afirmação não se trata propriamente de uma variação da descrição bakhtiniana do autor como o orquestrador de vozes que o precedem, tornada célebre pelas reformulações de Roland Barthes e Michel Foucault. A noção aqui expressa é a de que os livros são motivados por um arrebatamento místico que implica a passagem para outro estado de consciência. Esse estado alternativo de consciência exime o escritor de responsabilidades maiores e limita-o ao papel de redator do que as vozes the dizem, passando a cena da escrita antuniana a responder perante uma velha crença romântica, devidamente acoplada a referências a técnicas xamânicas e a momentos de êxtase: inspiração.

Enquanto espera pelos "sinais físicos" que anunciam o próximo livro, Lobo Antunes passa o dia instalado "de cotovelos na mesa e mãos no queixo, diante de um tampo vazio" (QUILC 110). Tem noção de que o universo do livro the vai exigir a pele. Para ganhar coragem, assinala no calendário um dia arbitário para principiar. Entretanto, ordena cuidadosamente os papéis e as canetas, anota frases, imagens, planos, declina versos de Horácio e Ovídio para português, deixa-se à espera das vozes que hão de guiar a mão (QUINLC 17). No dia marcado, instala-se no seu lugar, pronto para o sacrifício. A partir daí, é a rotina da escrita, disciplinada e ordenada: das oito da manhã às onze da noite, com pausas para o almoço e para o jantar, escrevendo e corrigindo, escrevendo e corrigindo. Escreve à mão, em letra pequenina, avança quase sempre muito devagar. As versões acumulam-se, o esforço é imenso, todos os dias são uma aventura em mares desconhecidos. Nos breves intervalos de que dispõe, contanos nas crónicas os detalhes desse esforço, faz pose, adorna como pode o seu corpo de escritor, pede ao leitor-etnógrafo que traduza aos não-iniciados seus 
mitos sagrados. Para todos os efeitos, o escritor é um atleta de fundo que vê o livro mais como uma maratona do que como um projecto de curto prazo, com plena consciência de que só no fim se pode ganhar o direito ao êxtase da revelação e a atenção dos críticos para cima de cinco mil anos.

Lobo Antunes pensa que o livro só é um livro na medida em que for capaz de albergar escritor e leitor na expedição às trevas mais negras da alma. $\mathrm{O}$ seu Livro perfeito pode assim ver-se como consequência de uma experiência apocalíptica e de um pensamento pastoral endémico. A paisagem sublime, diznos ele, só pode revelar-se quando o autor tenta "vencer Deus a toda a largura do tabuleiro" e aguenta "uns vinte meses de corpo a corpo com o texto" (TLC 22627). Como se explica em "Receita para me lerem," a experiência da leitura deve servir para dar nexo à vida do leitor. $\mathrm{O}$ ónus do livro está precisamente na intensidade dessa marcha ascencional até ao pico triunfante — onde a dupla de exploradores experimentará o júbilo em que o nevoeiro se dissipa e a planície, saturada, se abre ao êxtase da contemplação do Grande. No ângulo positivo, isto equivale a dizer ao leitor "Põe de lado a crónica e segue-me ao longo da Marca até completarmos o círculo se quiseres saber o que é realmente um livro," enquanto no ângulo negativo equivale a defender fundamentos transcendentais para atividade da escrita. Aliás, para adaptar uma conhecida imagem de Marcel Mauss, segundo Lobo Antunes a relação de reciprocidade que se estabelece com o leitor é a rocha fundamental sobre a qual se erige o livro. Parece por isso fazer sentido que o autor insista prolongadamente no argumento de que as crónicas, por não promoverem este género de excitação cruzadística, não são capazes de produzir a dimensão monádica de um livro. Observe-se, por exemplo, o seguinte passo, extraído de "António 56 1/2, em que o autor formula com clareza o que pensa sobre a arte de escrever livros:

Jogara tudo no acto de escrever, servindo-se de cada romance para corrigir o anterior em busca do livro que não corrigiria nunca, com tanta intensidade que não lograva recordar-se dos acontecimentos que haviam tido lugar enquanto os produzia [...]. Se pudessem tiravam-lhe os atacadores e o cinto como se faz aos presos a fim de o impedir de escapar-se de saber lá para onde ou de morrer por descuido, dado que não distinguia o açúcar da areia nem os diamantes do vidro, ocupado como andava a gravar as palavras 
tão profundamente que se pudessem ler, como Braille, sem o auxílio dos olhos. Que o dedo corresse pelas linhas e sentisse o fogo e o sange. (SLC 119-20)

Inegavelmente, temos muitos e bons motivos para continuarmos a usar as crónicas de maneira a obtermos boas previsões acerca do sistema dos romances. Como diz Sérgio Guimarães de Sousa (13), esta paisagem intermédia ajuda-nos, em diversos aspetos, a corrigir a "distância filológica" que nos separa dos mecanismos mais complexos dos romances de Lobo Antunes e a harmonizar num gesto elástico teses à primeira vista incompatíveis-por exemplo, a tese da expansão rizomática típica do discurso antuniano com a tese da natureza orgânica dos seus livros.

A este respeito, o modo como a poética antuniana exclui preocupações com níveis extratextuais evidencia o domínio da forma sobre os intérpretes. Em sintonia com um crítico formalista como Kenneth Burke, Lobo Antunes pensa que o talento do escritor se mede pela capacidade de levar até ao fim a transformação da realidade em símbolo e verdade estética. O nascimento da obra de arte através da ritualização da revelação, de que fala o autor de CounterStatement, é belamente ilustrado pela emblemática imagem antuniana de um livro que se pode ler no escuro, seguindo com o dedo a verdade que se escreve a si mesma, numa corrente de fogo e de sangue. E a pretensão de Lobo Antunes em relação ao efeito dos seus romances sobre o leitor, cujo momento climático, à luz do idílio simbiótico que acima descrevi, é o momento em que o autor e o autor se espelham mutuamente em cada página do livro, remete-nos para aquilo que Burke identifica como "perfeição." Antes de mais, é preciso realçar que, em termos muito precisos, essa aliança se enuncia quando o livro se sobrepõe fenomenologicamente ao autor e ao leitor "até nenhum de nós saber qual dos dois somos" (SLC 115).

De qualquer modo, a ênfase espacial para a qual Lobo Antunes dirige a nossa atenção, e que tem sido de bom-tom seguirmos de perto, talvez deva ser comentada a partir de outro ponto de vista. Em lugar da viagem psicanalítica ao interior de si mesmo por meio da qual o leitor pode "abandonar as roupas de criatura civilizada" e "escutar a voz do corpo" (SLC 115), o livro que já não precisa de correções pode, com mais exatidão, ser definido como a repetição ad nauseam de exercícios de proximidade para testar as fronteiras do seu próprio 
sistema por meio da encenação de uma fantasia uterina. Um modo, portanto, para exprimi-lo em termos naúticos, de enunciar um porto de abrigo para o terror branco do alto mar. Assim, os livros são concebidos por Lobo Antunes como relações idealizadas com o leitor "em que cada um seja ambos e regressemos desses espelhos como quem regressa da caverna do que era" (SLC 115). Para Lobo Antunes, o regime do romance resulta não da estratégia de justapor fragmentos complexos, ao estilo de Walter Benjamin, mas do trabalho de integrar as vidas sem história de famílias anónimas em rotinas de catarse, restituindo-lhes "a intensa dignidade de uma criatura inteira" (SLC 115) à medida que "uma energia subterrânea, vulcânica" (TLC 71), ascendendo das trevas profundas "em largos círculos concêntricos que se estreitam e aparentemente nos sufocam [...] para melhor respirarmos" (SLC 115), se aproxima com esplendor das formas frias da realidade. Corrigindo Bahktin com um argumento de Croce, Lobo Antunes defende que o livro deve converter-se numa entidade Una, produzida à custa do esforço para exprimir a totalidade dos assuntos humanos numa Grande Narrativa. Titânico, o romance é o sujeito épico que visa dissolver os limites da sua forma e transfigurar-se pelo exercício constante, pela pressão colossal e pela agudeza das palavras, na "própria essência das coisas" (TLC 74). Mesmo neste contexto e ainda que tome de empréstimo a tonalidade vaga do lirismo, uma palavra como essência não deixa de ser uma palavra tosca e enferrujada. No entanto, "essência" traduz com precisão o fenómeno que Lobo Antunes pretende ilustrar, por exemplo, na crónica o "O Mecânico," quando sugere que os livros nos permitem pôr em marcha uma clarificação tal da realidade que, ao fechar o livro, se tudo correr como se espera, "nem a vocês mesmo se vêem" (TLC 41).

Vendo-se como o leitor mais inteligente dos seus livros, Lobo Antunes pensa que ainda que o leitor comum irracionalmente possa gostar do tom rememorativo, do entusiasmo, da autenticidade e do lirismo das crónicas, o problema é que "essas coisinhas" estão à sombra dos seus "livros," não tendo qualquer importância nem para as histórias da literatura, nem para a sua própria imortalidade literária. Para escrever um livro, Lobo Antunes obriga-se a despir "interiormente de tudo o que não é ele" (QUILC 17). Fundindo adornianamente forma e conteúdo num modo de ab-reagir às tempestades do mundo, ele pensa que a esperança do mineiro que escava sozinho o interior das palavras até conseguir tocar com os dedos o "fundo avesso da alma" e a "treva fatal" é 
correlativa da esperança de obtermos uma imagem completa da realidade e correlativa da esperança de obtermos sentido para a vida através das palavras.

Para os leitores criados por Memória de elefante, Explicação dos pássaros, As naus e Manual dos inquisidores, este dispositivo de catarse de uma sequência de acontecimentos que marcou toda a segunda metade do século XX português correspondia a referenciais históricos, políticos e afetivos comuns. Mas à medida que os romances anteriores foram corrigidos pelos seguintes e o impulso de reconciliação levou as estruturas discursivas para picos sucessivamente mais esotéricos e tornou sucessivamente mais complexa a função de representação dos seus romances, Lobo Antunes foi sentindo necessidade de converter palavras e figuras abstratas que têm sido importantes para ele ao longo da sua carreira (por exemplo, palavras como "vozes," "luz," "treva" e, em termos cada vez mais autoritários e talismânicos, "silêncio") em palavras e figuras abstratas que devem ter utilidade para uma multidão de leitores potenciais.

O problema é que Lobo Antunes está neuroticamente convicto de que o livro é aquilo a que o seu trabalho da escrita tem estado a conduzi-lo, que a sua fasquia é a fasquia dos leitores e que a sua receita privada para descrever emoções tem aplicação universal. Concordo que "o caminho do silêncio" (Sousa 150) é um lema sonante e arrojado, no entanto, a hiperbolização gradual da forma promovida pela busca do silêncio parece ter convertido as esplenderosas narrativas de Fado alexandrino, A ordem natural das coisas ou $O$ esplendor de Portugal no tipo de litania estéril que vem configurando os livros mais recentes. Isso acabou, por um lado, por trair alguns dos aspetos realistas dos livros com os quais muitos leitores se identificaram e, por outro, foi paulatinamente bloqueando a consonância histórica entre os livros de Lobo Antunes e o Portugal pós-imperial emergido da revolução de Abril de 74, que a crítica tanto enalteceu. Pressionado pelo sucesso apoteótico das crónicas, que o confunde e, acima de tudo, põe em causa a validade do vocabulário que usa para justificar os paradigmas da sua teoria estética, Lobo Antunes adoptou uma atitude tão paternalista quanto impiedosa e passou a referir-se às suas crónicas por meio de expressões pejorativas como "prosa alimentar," "coisinhas sem nenhuma pretensão," "piscinas para crianças," "coisa ligeira que não faça pensar muito" ou "desenhos meio distraídos na margem do papel," entre outras expressões de valor equivalente: expressões que sugerem que as crónicas não são textos escritos até ao fim e que não devem fazer parte do sistema relacional configurado pelos 
seus livros. ${ }^{2}$ Qualquer uma destas expressões tem a função de deflacionar o pathos da crónica face ao do romance, sugerindo-nos que as duas formas não estão em pé de igualdade no que respeita a pretensões, procedimentos técnicos e consequências pragmáticas, pelo que o conceito autodescritivo de "livro" não é extensível aos Livros de Crónicas, "esses riscos a que não consigo dar importância” (QUILC 91). Inflamado, Lobo Antunes nem sequer nos autoriza a comparar uma forma com a outra, no sentido em que geralmente se faz com os livros de poetas que também são romancistas, ou com os livros de poetas que também escrevem contos, peças de teatro ou crítica literária. Alternativamente, ele teima em utilizar a crónica para realçar, por contraste, o esplendor técnico e simbólico do romance, embevecido com a sua habilidade para prender solidamente a linguagem em torno de um conhecimento preciso da vida e da realidade.

Pretendo denunciar nas próximas páginas as consequências e os limites desta descontextualização das crónicas perpetrada pelo próprio autor, que acaba por transformar o que seria uma relação amistosa entre duas formas interdependentes numa relação caracterizada pela animosidade e pela subserviência, para a qual tenta arrastar a crítica especializada. Mas antes de avançarmos para a fase seguinte, resumam-se os pontos principais do argumento que tenho vindo a apresentar, assinalando alguns dos problemas provocados pela ambição teórica de Lobo Antunes e pelo modo como olha de cima para o leitor e para os livros que escreve quando estabelece uma comparação entre as crónicas e os romances. Quando postula que não há uma consubstancialidade entre eles e que a utilidade da crónica está em iluminar a matriz complexa do romance, Lobo Antunes não está apenas a defender que a ontologia, a natureza, a estrutura, a genealogia e a intenção do romance são profundamente diferenciadas das da crónica. De uma assentada, está também pôr em ação um instrumento de controlo do leitor, a fazer afirmações implícitas sobre a natureza e as propriedades formais do Romance, sobre as condições de estabilidade do texto literário e, ao arrepio não só de Iser, de Fish e de Jauss, e, genericamente, da sua própria teoria do romance, está ainda a oferecer-nos um argumento sobre a irrelevância da figura do leitor no processo de determinação do que deve contar ou não como literatura.

\footnotetext{
${ }^{2}$ Nem é necessário citar as referências específicas - o leitor encontra este género de expressões com muita facilidade: basta folhear distraidamente os volumes de crónicas ou o volume de entrevistas a Lobo Antunes preparado por Ana Paula Arnaut.
} 
Em termos académicos, a consequência imediata é que se quisermos apoiar a pretensão de Lobo Antunes teremos de dividir a sua obra em duas séries paradigmáticas: uma relativa a textos de águas profundas, cuja intencionalidade está determinada pela instância totalizadora da Opera omnia, dependente de longos anos de prática; e outra relativa a textos de águas rasas, destinados à autocomplacência dos leitores de domingo, dependente de uma predisposição natural para a escrita memorialística e para a ressonância emocional. Mesmo nos casos em que a interpenetração intertextual é notória, explica ceticamente Lobo Antunes, às crónicas não deve ser concedido o estatuto de "literatura," sendo mais apropriado que as pensemos não como textos que ainda não passaram pelo processo simbólico de que o romance é o estádio maior, mas, quando muito, como um subproduto da gesta heróica de criação do livro. Se o romance é correlato de uma vida de ascese, ritual e obstinadamente determinada pela regra de um projecto simultaneamente editorial, existencial e escatológico, o livro de crónicas, por sua vez, é um fascículo que resulta do encontro casual entre um divertimento efémero e os benefícios financeiros incluídos num contrato de prestação de serviços. Se o romance é elaborado para aguentar a pressão do espaço e do tempo ao longo de centenas de páginas, a crónica, por sua vez, tem espaço e tempo contingencialmente normalizados. Se a motivação central do romance - de qualquer um deles - é a de ocupar um lugar predeterminado no círculo iniciático das Obras Completas, a crónica, ainda que ao romance esteja ligada por um cordão umbilical, parece servir para o escritor conversar sobre as coisas que acontecem enquanto escreve um romance.

Não surpreende, pois, que sempre que fala da arte do romance, Lobo Antunes murmure uma rapsódia composta de palavras fascinantes como revelação, epifania, luz e treva, ao mesmo tempo que mantém a crónica no seu lugar, isto é, como um texto sem obrigações de maior, concebido para distrair mundanos leitores de domingo - esse voyeur que se diverte espreitando pela janela estreita e baça que se abre para o gabinete de trabalho do escritor. A distinção entre o romance e a crónica é-nos assim apresentada, portanto, mais como uma questão de necessidade do que de forma. Quando muito, diz-nos um Lobo Antunes desdenhoso, os tentáculos rasteiros da crónica poderão acomodar-se nos patamares inferiores do monumento erguido pelos romances. As crónicas, mesmo que o seu tom rememorativo, a ternura, a transparência e a beleza toquem intimamente o leitor, não passam de um mero diário de bordo da aventura da 
criação, produto da contingência e do acaso, objetos periféricos em relação à esfera que arredonda o seu programa formalista de escrita: "São 30 livros que formam um continuum, um único trabalho, um único volume, a razão de uma vida" ("O meu futuro").

A ideia que dá é que Lobo Antunes se deixa cair na célebre armadilha da falácia intencional ao aplicar a metáfora do eremita no eremitério para reduzir a crónica ao regime de fascinação do romance. O resultado é que a descrição de Lobo Antunes do funcionamento da narrativa pode ser apropriada para o romance, mas é quase totalmente inapropriada para a crónica. Por que razão Lobo Antunes teima em insistir que as crónicas não passam de bricolage, ao mesmo tempo que admite para si mesmo que estão suficientemente próximas da sarça ardente para nos ajudarem a compreender o coração do coração dos romances? Por que razão nos leva a pensar que se não lermos mais do que estes textos de duas ou três páginas temos boas razões para nos sentirmos frustrados? Por que razão repete que o romance responde ao apelo angustiado do homem e a crónica não responde a coisa nenhuma? Só alguém que olha com revolta e ressentimento para as potencialidades da crónica pode sentir necessidade de instituir uma fronteira tão clara entre essas duas formas literárias, traduzindo-a em cenas de escrita unilaterais: enquanto os romances são o campo onde se batalha pelo favor dos Deuses, as crónicas são redigidas de um jacto, na mesa da cozinha, durante uma interrupção deliberada do ritual da escrita: "Acabando esta crónica, regresso ao livro: ali está ele à minha espera" (QUILC 287). O romance traduz uma obrigação moral e o trabalho só termina, para pouco depois recomeçar, quando o escritor é expulso pelo livro. A crónica, essa, o escritor pode abandoná-la quando quiser: como ele mesmo nos diz, basta "deixar tudo em branco a seguir" (QUILC 20). Compreende-se, pois, que quando o leitor, mesmo depois destes argumentos, insiste em preferir as crónicas, Lobo Antunes responda com sarcasmo, e sobretudo com desânimo.

Inevitavelmente, as avaliações autorreflexivas têm uma série de limitações. O simples contacto reiterado com o ar rarefeito da montanha pode levar o grande mestre a esquecer o ar pesado das planícies terrenas (da mesma maneira que o contacto reiterado com o ar denso das planícies pode afetar gravemente o crítico). Ora, por muito que esta posição resulte da enorme despesa retórica que Lobo Antunes impõe aos seus livros e possa até contribuir para os lermos de forma mais responsável, o problema é que isto exige que prestemos menos atenção aos 
livros que estamos a ler do que à história de como o romancista se tornou aquilo que é. Se quisermos mostrar que as crónicas não são meras lâmpadas acesas sobre as páginas do romance, temos de começar por dizer coisas diferentes acerca da pretensão sinóptica dos romances. Nesse sentido, julgo que temos muito a ganhar se o entrelaçamento entre as narrativas do autor e do leitor que constitui o refrão teórico de Lobo Antunes não for visto como a chave metafísica que nos dá acesso ao sentido último da literatura ou aos fundamentos retóricos que prendem a linguagem às formas do mundo, mas como um género de experimentaçãolinguística, afetiva, material — que traz para o primeiro plano uma visão ecológica da existência. Consequentemente, no trabalho do crítico, esse refrão não deve ser filtrado, por exemplo, pela teoria de Jan Mukarovsky de que a realidade poética alude à(s) diversa(s) realidade(s) do(s) leitore(s), pela teoria de Wolfgang Iser de que a concretização do texto se constitui articulando a realidade do texto e a disposição do leitor numa dimensão virtual, ou sequer pela teoria da referência de segundo grau de Paul Ricoeur, mas pelo o tipo de vocabulário geralmente usado por ecocríticos e filósofos ambientais.

Há aqui várias questões que quero considerar. Do alto do pedestal, como se sabe, Lobo Antunes tem advogado a favor da ideia de as crónicas nos ajudarem a entrar em contacto com os romances. Mas cá em baixo, na planície cinzenta, muitos leitores têm-se apercebido de que os romances, ultimamente, tendem a ficar mais dependentes de uma linguagem privada do que do tipo de conhecimento universal que Lobo Antunes tem a pretensão de oferecer. Instintivamente, esses leitores começam a pensar que pode haver crónica sem haver romance, que as crónicas podem perfeitamente responder por si próprias. Para explicar esta perspetiva, irei nas próximas páginas reconstruir a distinção romance-crónica de Lobo Antunes. Argumentarei que se o romance pode ser visto como uma série de narrativas que se transformam em litania, as crónicas devem ser vistas como uma série de litanias que se transformam em narrativa.

\section{Anti-reverência}

Como se imagina, passadas três décadas, a crónica de Lobo Antunes ganhou um lugar próprio na rotina do leitor e a sua forma apresenta-se, cada vez mais, como uma superfície densa estabilizada em torno do núcleo dos romances. Compreende-se, por isso, que as reações do público às opiniões críticas do autor 
dependam do tipo de comunidade a que se pertence, embora, regra geral, haja tendência para se formar um consenso em torno da sua desvalorização. Os defensores de Lobo Antunes desvalorizam os comentários do autor com a complacência divertida que se deve a um génio e continuam a seguir semanalmente os "traques" do autor. Os detratores de Lobo Antunes desvalorizam-nos com o esgar sardónico de quem não perde tempo a ler Lobo Antunes, muito menos a ler as suas entrevistas. Maria Alzira Seixo (2010), no notável As flores do inferno e jardins suspensos, em gesto conclusivo, defende que o tipo de secundarização a que Lobo Antunes vota as suas crónicas deve ser visto com a mesma bonomia que muitas declarações públicas dos escritores, isto é: presumindo que são apenas mais um aspeto da auto-imagem heroica do escritor, estreita e profissionalmente ligada às campanhas promocionais dos seus livros. E que o leitor, por isso mesmo, deverá desvalorizar.

Seja como for, não é por acaso que a discussão que Lobo Antunes conduz sobre a relação entre os romances e as crónicas tem coerentemente tomado a forma de um monólogo íntimo. O que parece cada vez mais interessar-lhe é o modo como cada novo romance poderá tornar-se parte da paisagem interior do que ele mesmo entende como "literatura" e como "obra" e não como os textos que escreve podem alterar "o sentido que cada um tem daquilo que é possível e importante" (Rorty 113). O problema é que Lobo Antunes parece esquecer-se de que a História Natural dos seus livros, tal como é mobilizada por esse discurso, mesmo se nos dá subsídios para aproximá-lo de uma família de escritores tão ilustres e valiosos como Honoré de Balzac, Leo Tolstoi ou Joseph Conrad, não é de maneira nenhuma a única instância de autoridade no que diz respeito a protocolos de leitura e é-o ainda menos no que diz respeito a modos de descrição, interpretação e valorização dos seus livros. Como argumenta Stanley Fish (1980), tanto a durabilidade da interpretação como as rotinas interpretativas em diferentes momentos históricos são consequência da maneira como cada comunidade de leitores produz continuamente a forma e o sentido do seu objecto. A constituição e a importância das comunidades interpretativas e a legitimidade das interpretações que produzem vale tanto para os romances como para as crónicas. No caso de Lobo Antunes, mesmo que isso signifique entrar em desacordo com a auto-interpretação do autor, a verdade é que não há como refutar o facto de que os leitores se têm interessado cada vez mais pela série das crónicas do que pelos romances propriamente ditos; nem como refutar o facto de que não 
há nenhum modo de estabelecer um conjunto de princípios objetivos que nos permita explicar a preferência do público.

Procurando situar as crónicas no conjunto da obra de Lobo Antunes e tornar explícitos os paralelismos que as ligam aos romances, Maria Alzira Seixo segue a lição de I. A. Richards e sublinha a noção da literatura como comunicação exata de uma experiência inicial e da leitura como um método de decifração dos sentidos do texto. Seixo recusa qualquer desinvestimento analítico nesta forma menor e argumenta que o seu "modo de dizer particular" tem a capacidade de constituir entre autor e leitor uma "corrente de ligação interior" a qual, desdobrando-se em imagens de alegria e de sofrimento, evoca um "sentir comunitário" (132). Mas este tipo de generalização segue os passos do autor na redução das crónicas a formas afins dos romances. Pressupõe que o crítico diligente tem o dever de manter o mesmo tipo de relação de vizinhança e, consequentemente, aprofundar a maneira de usar as crónicas para iluminar os detalhes das isotopias narrativas, das marcas estilíticas e dos processos simbólicos dos romances de Lobo Antunes. Não é por acaso, de resto, que Seixo remata o seu argumento esclarecendo que se o leitor das crónicas quiser tornarse um dos felizes poucos (isto é: se aceitar mudar as suas práticas de leitura) rapidamente irá descobrir que os romances podem dar muito mais sentido à sua vida do que as páginas de uma simples crónica (133).

Penso que é útil refrearmos a nossa esperança neste ponto de vista. Por um lado, embora a homologia assim projetada entre objectos literários ontologicamente distintos seja útil para reforçar a unidade e a consistência da obra antuniana - o que, em certo sentido, a valoriza sob o ponto de vista da crítica e da historiografia literária - tem também a consequência de nos obrigar a transformar a experiência da leitura das crónicas num evento ulterior à experiência de leitura dos romances. Isso pode levar a que usemos estes textos não de forma autónoma e recíproca, mas, muito pelo contrário, da mesma maneira que se usa a marginália em operações filológicas: para tornar mais legíveis os textos maiores, cruzar influências e referências históricas e biográficas, e facilitar a decifração dos significados múltiplos, da ambiguidade e da complexa retórica de temporalidade que caracteriza os grandes romances de Lobo Antunes. Isto é apenas uma maneira de remediar as consequências do modo como Lobo Antunes desenvolve a autoconsciência do seu trabalho e não evita que o texto continue a ser transformado em paratexto. 
Contra este modo de ler as crónicas a partir da instância dos romances, o que quero no resto deste ensaio sumariamente propor são as primeiras linhas de um manual de instruções que possa mostrar como a série das crónicas de Lobo Antunes pode ser usada, de uma maneira melhor que os romances, como dispositivo para desenvolver um modo de pensamento especificamente ecológico. Estou a usar esta expressão, "pensamento ecológico," no sentido pragmático em que a usa Timothy Morton em The Ecological Thought (2010), isto é, como tipo de pensamento que nos encoraja a partir do princípio de que tudo está interconectado. Ora, a primeira regra desse putativo Manual de Instruções sugere que se emancipem as crónicas como uma forma literária autónoma, libertando-as da avaliação autorreflexiva do autor e das marcas dos romances que nelas se inscrevem. Evitando enquadrar as crónicas no esforço de extrair segredos dos romances - ou, se quisermos, evitando enquadrar as crónicas no caminho do Grande que é a História Natural da ficção, ou, se quisermos, evitando enformar as crónicas na busca de um sentido de realidade-estaremos então livres para considerar os livros de crónicas como a forma literária mais simbiótica e democrática que Lobo Antunes produziu no que concerne a uma consciência ecocêntrica.

O cerne do meu argumento é que o facto das crónicas não serem constrangidas por um desejo de totalidade, mas produzidas por meio de improvisações e samplings que fluem como se fugissem ao controlo do pensamento e da mão, lhes deixa o caminho aberto para pôr em movimento um pensamento ecológico, o tipo de pensamento que nos ajuda a repensar a nossa relação com os dispositivos de poder que descrevemos a partir de categorias como "natureza," "cultura," "capitalismo" e "progresso," rumo à perspetivação democrática do Eu como Outro. ${ }^{3}$ A crónica, se este desajustamento for entendido como potencial de abertura radical, ganha o sentido de uma reação "verde" ao discurso reificado da "sociedade do cansaço," expressão cunhada por ByungChul Han (2014) para descrever o excesso de positividade e o paradigma patológico da sociedade contemporânea em contraste com a retórica da sociedade disciplinar que continua a dominar o discurso crítico sobre a pós-modernidade.

\footnotetext{
${ }^{3}$ Para além das considerções de Morton sobre "ecological art" (105), parte significativa das observações que se seguem foi inspirada pela análise de Fallingwater, a célebre casa desenhada por Frank Lloyd Wright, em Forests, de Robert Harrison, especialmente a noção de democracia como "a particular kind of shelter grounded on the earth" (235).
} 
Se o interesse dos livros de Lobo Antunes depender da contribuição significativa para um pensamento ecológico, julgo que é nas crónicas que o leitor vai mais rapidamente encontrar o efeito derrogativo sobre o "excesso de estímulos, informações e impulsos" (Han 31) característicos da sociedade ocidental do cansaço.

Isto quer dizer que, ainda que não se articulem com qualquer agenda política explícita ou implícita, seja global ou local, nem declarem uma preocupação especial com a Natureza ou com temas ou motivos tipicamente reconhecidos como ecológicos, a série de crónicas de Lobo Antunes parece-me mais compatível do que os romances com o que está na ordem do dia na era do antropoceno. Porque o excesso de estímulos, informações e impulsos, como o leitor reconhecerá, constitui, praticamente, uma das normas do romance de Lobo Antunes, e porque há também um paralelismo entre a violência neuronal que Byung-Chul Han atribui à sociedade contemporânea e a violência a que são submetidas as instâncias de enuncição em romances como Ontem não te vi em Babilónia ou Não entres tão depressa nessa noite escura. Mas as crónicas recorrem constantemente a técnicas de justaposição para colapsar em termos radicais as relações entre forma e conteúdo que constituem o pathos do romance. O movimento é tautológico: é porque evitam as aspirações à limpidez absoluta do romance que as crónicas se abrem compulsivamente ao ambiente extraliterário a que os romances gradualmente se fecharam.

Para desenvolver a última parte do meu argumento, é tempo agora de considerar aquela célebre passagem de "Receita para me lerem" que descreve os efeitos do livro sobre o leitor como a "experiência da antropofagia através da fome continuada." Embora referida amiúde pela crítica, parece-me que desta passagem raramente se têm extraído consequências significativas. ${ }^{4}$ Numa primeira leitura, não é difícil conceber esta imagem como a aplicação do idealismo intersubjetivo transposto para os termos de um sistema de sacrifício. Neste sentido, abandonar as roupas de criaturas civilizadas corresponde, evidentemente, a abandonar as aparências em função de uma substância absoluta. Se cinicamente levarmos esta ideia às últimas consequências, podemos com facilidade admitir que essa passagem pode ser lida como uma paráfrase

\footnotetext{
${ }^{4}$ Estou a referir-me, muito concretamente, ao modo como Norberto do Vale Cardoso relaciona o imaginário canibal de Fado alexandrino com a questão pós-traumática vivida pelo antigo militar; ou, ainda, como uma marca da multiplicidade que caracteriza a forma do romance antuniano (28).
} 
imperfeita da descrição de Viveiros de Castro da prática antropofágica tupinambá, isto é, "um processo de transmutação de perspetivas, onde o 'eu' se determina como 'outro' pelo acto mesmo de incorporar este outro, que por sua vez se torna um 'eu', mas sempre no outro, através do outro" (Viveiros de Castro 159). Pondo "autor" onde está "devorador" e "leitor" onde está "inimigo," o regime de internalização do livro que se expõe em "Receita para me lerem" sugere-nos que o processo de equiparação entre figura e leitor se realiza através da "captura de recursos simbólicos do exterior," nos termos de uma "economia da alteridade predatória" (Viveiros de Castro 161). Um breve relance de olhos permite-nos concordar que esta dinâmica básica funciona tanto para descrever o romance como para descrever a crónica.

Mas o que é preciso ter em consideração é que a economia da alteridade predatória da crónica procede de uma fonte diversa da dos romances. Se a superestrutura do romance se apresenta como uma máquina estético-terapêutica de desdobramento de profundidades sucessivas a cujos sistemas de regras e de motivos autor e leitor devem submeter-se no decurso da cruzada pelos altares do absoluto, a série das crónicas apresenta-se maioritariamente como um desporto de ligações horizontais de superfície em que o objectivo principal é o de expandir o espaço por meio de uma oscilação de perspetiva. ${ }^{5}$ Por outras palavras: se o dispositivo rizomático do romance parece ser determinado pelo valor místico de um telos, a ecopoética horizontal das crónicas limita-se a evoluir por meio de metamorfoses contínuas nos termos de um regime antropofágico de expansão agonística. É nesse sentido que podemos dizer, por meio de outra analogia, que a narrativa fractal da crónica é tornada visível pela busca obsessiva do romance. É precisamente a indiferença do romance pela história que converte a crónica numa forma mais disponível para reunir em torno de si os leitores (ainda que seja alinhavada com displicência na mesa da cozinha, e ainda que o autor qualifique como medíocre o seu modo de proliferação). Se quisermos agora transpor o argumento de Morton, segundo o qual o pensamento ecológico é o tipo de pensamento que está à altura da consciência democrática que é para nós tão urgente, uma democracia caracterizada pelo vocabulário e pela ética do

\footnotetext{
${ }^{5}$ Veja-se como a imagem dos livros como "afluentes de um único texto ainda não completo e que, por mil anos que viva, ficará irremediavelmente truncado" que surge, por exemplo, em "Deste profundo abismo, Senhor,” de Quinto Livro de Crónicas (293-95), ilustra com uma retórica solene esta afirmação.
} 
coexistencialismo, capaz de promover uma intimidade progressiva com o estranho (46-47), não podemos deixar de reconhecer nas crónicas uma disposição terraformante que está mais à altura desse novo vocabulário que o andamento repetitivo do romance.

Em termos decisivos para o meu argumento, Maria Alzira Seixo, no estudo de referência que já citei, pergunta-se se "o modo de representar a vida humana das crónicas” será mais eficaz que o dos romances (227). Embora não conclua nem que sim, nem que não, Seixo vem propor que a situação comunicativa produzida pelas crónicas resulta da habilidade especial para configurar um ambiente de "ressonância evocativa" (227), sendo esse o ritmo desse encontro, diz-nos Seixo, fruto de uma série de pontes que assimilam até à indiferenciação as margens do facto e da ficção. Parece-me que é precisamente pela capacidade radical de absorver outras perspetivas e expandir em planos horizontais a vida humana que a crónica começa a dominar a economia predatória da obra antuniana. Mencionei acima que há boas razões para compararmos o processo de escrita de Lobo Antunes a um ritual xamânico. Aproveite-se agora essa analogia para sugerir uma comparação adicional entre a crónica e romance. Se o xamã é essencialmente um "comutador de perspectivas" que opera a "comunicação transversal entre incomunicáveis" (Viveiros de Castro 171), que é capaz de ver as figuras dos livros como elas se vêm a si próprias, podemos descrever a rede produzida pelas crónicas como o relato transposto para o papel de uma experiência xamânica de baixa intensidade e longuíssima duração. Se imaginarmos que, por razões expositivas, podemos levar um pouco mais longe essa analogia e recorrer ao contraste que Viveiros de Castro, a partir de Stephen Hugh-Jones, desenvolve entre um xamanismo "horizontal" (que Viveiros de Castro depois reclassifica como "transversal") e um xamanismo "vertical," podemos aflorar ainda os termos de um contraste adicional entre os dois tipos de livro que Lobo Antunes tem publicado ao longo da sua carreira. ${ }^{6}$

Por essa via - que me leva a retomar a tese da configuração rizomática do texto antuniano, mas dela extraindo perguntas e consequências alternativasenquanto o autor do romance pode ser visto como um xamã operando na dimensão vertical, o autor do livro de crónicas corresponde a um xamã operando

\footnotetext{
${ }^{6}$ Segundo esta distinção, o xamã "horizontal” é uma figura carismática responsável por práticas de imanência, enquanto o xamã "vertical" representa a figura sacerdotal responsável pelos rituais de transcendência de uma comunidade (Viveiros de Castro 174-76).
} 
na dimensão transversal. Inclino-me a dizer que o livro assim concebido não traduz uma dolorosa experiência ascética mediada por um desempenho estilístico de alta magnitude, mas sim um regime de justaposição mediado por uma experiência perspetivista radical. Um livro singular que, ao contrário dos romances, não sofre do tormento das "hesitações, recuos, influências, a certeza que ainda não era aquilo, ainda não era aquilo" (QUILC 285), mas prolifera e reverbera por muito tempo, ao colapsar espaços e vozes em torno de si. Um livro, simultaneamente referencial e alegórico, cuja gramática não é concebida como uma força de elite lançada em terrenos hostis para demarcar a realidade, mas que serve, muito simplesmente, para redescrever atmosferas e situações identitárias com as quais não estamos familiarizados. Um livro que não incorpora o cinismo sumptuoso dos romances mais recentes, nem quer saber se chegou ou não ao fundo do tacho. Um livro cujo tema central não pode ser formulado como uma meditação sobre as relações entre vida e morte, como sublinha Seixo sobre o universo romanesco antuniano, mas se apresenta como uma sensibilidade especial para o entorno físico, expondo a contingência de qualquer versão da realidade ou teoria do conhecimento. ${ }^{7}$ Um livro cujo ecossistema se autoregenera e se expande por replicação transversal (por meio de sequências de jardins que se expandem em vastas florestas) e por isso contrasta, rigorosamente, com o mosaico dobrado sobre si mesmo típico de romances como Não entres tão depressa nessa noite escura. Em suma: o livro de crónicas, ao contrário do romance, é um livro que não está à procura da última porta antes da noite.

Duas conclusões e uma coda provisórias podem desde já ser avançadas. A primeira conclusão que podemos extrair do novo contraste que aqui apresentei entre as duas séries paradigmáticas em que Lobo Antunes nos sugere dividir a sua obra é que isso nos torna livres para deixarmos de ver as crónicas como artefactos resultantes de um ludismo circunstancial, como bocados de prosa descansando entre dois patamares de uma demanda literária elevada e profunda, para a qual os limites do mundo são os limites do romance. Se algumas crónicas se tornam ulterior ou posteriormente desenvolvidas nos romances é unicamente pela razão de que o seu potencial de abertura e de transição por múltiplos ambientes já as coloca a meio caminho para se tornarem elas mesmas romances.

\footnotetext{
${ }^{7}$ Esclareça-se que se este motivo é transversal aos livros de Lobo Antunes, nas crónicas assume uma importância ainda mais dominante e decisiva.
} 
A segunda conclusão é que a aceitação destas premissas nos torna também livres para vermos em que medida cada crónica se apresenta, na verdade, como um artifício cuja tarefa estratégica consiste em despir, em modo ironista, o romance da sua aura e expor as razões pelas quais o género da crónica pode ser visto como um exemplo de arte ecológica. Por último, a coda desta história que tenho vindo a contar sobre as crónicas de Lobo Antunes é que, se Morton tiver razão e, num futuro próximo, todos nós nos virmos sob a égide do pensamento ecológico (135), a distinção que aqui tracei expõe com clareza as razões pelas quais, nolens volens, sob um ponto de vista ecológico, a potencialidade terraformante e a mindfulness produzidas pela crónica antuniana se podem converter em uma narrativa mais significativa para a história literária do que a tentativa de Lobo Antunes para superar com um novo idealismo as ilusões e os impasses do romance moderno.

Tenho noção de que isso me obrigará tanto a corroborar a tese de que a crónica e o romance são pólos distintos do seu trabalho, como a declarar a necessidade de superarmos a consagração antecipada que Lobo Antunes nos exorta a fazer do seu livro total. No entanto, por si só isso já tira ao romance a sua autoridade. Se os ventos soprarem de feição, há que lembrar que a bravata de Lobo Antunes pelo género de Flaubert, de Tolstoi, de Marcel Proust, mesmo sendo convincente e bela e terna e feroz, ainda assim não deixa de ser redondamente falhada, como redondamente falhadas têm sido todas as tentativas de projetar o desespero da finitude humana no jardim edénico de um horizonte perdurável. Quanto aos críticos, alguns dos quais continuam a apostar no argumento antuniano sobre a perenidade dos romances face à volatilidade das crónicas, devemos desculpá-los por serem ocasionalmente seduzidos pelos pormenores biográficos e pelo tempo subjectivo revelados em crónicas tão estimulantes como "Receita para me lerem," "O próximo livro" ou "Tudo o que cresce precisa de muito tempo para crescer." E a verdade é que também não é tão invulgar assim que, ao correr da pena e meio embaraçados, esses críticos implicitamente nos digam que encontram mais abrigo e sapiência na floresta das crónicas do que na redondez dos romances. De qualquer maneira, não quero aqui advogar a ideia de que o autor passa completamente ao largo do que tenho vindo até aqui a afirmar. É sem surpresa que constato que a melhor lição sobre as questões que fui discutindo ao longo destas páginas já nos foi claramente antecipada pelo sagaz espírito autocrítico de Lobo Antunes. Numa crónica em 
que explica que o que lhe interessa num livro é o funcionamento do mecanismo interno e a maneira de resolver os problemas técnicos, Lobo Antunes confessa, em tom de desencanto, que se "a maior parte dos leitores exigem resultados, o meio de os atingir é-lhes indiferente" (QUILC 318), o que nos mostra que tem perfeita noção de que a sua busca pelo sublime literário se foi reduzindo a uma elaboração teórica pessoal que, como qualquer teoria, tem tendência a predizer e gerar a forma e o sentido do texto que as suas asserções exigem (Fish 68).

Apesar dos argumentos que até agora apresentei, tenho de reconhecer que as minhas conclusões podem suscitar reservas entre os críticos. Por um lado, podem achar-me movido pelo desejo perverso de minar a autoridade do autor sobre a própria obra. Lobo Antunes bem pode garantir-nos a pés juntos que só o ritual do romance pode criar o espaço onde o pulsar autêntico da vida humana pode emergir. Essa visão não está necessariamente errada-mas também não está necessariamente certa. Quer-me parecer que a insistência na natureza decisiva da excepcionalidade do romance e da teoria que o gera, por muito afetuosa que se mostre para os leitores mais fiéis, pode qualificar-se como um efeito retórico, potente, sem dúvida, mas secundário, se a pergunta a que se quer responder for sobre o valor intrínseco da crónica. Podem também dizer que muito do que digo soa veladamente aos lugares-comuns da crítica antuniana. Há certa razão nisso. É óbvio que muitas crónicas antecipam ou modelam o que depois surge nos romances. É óbvio que as tonalidades elegíacas e os truques linguísticos do romance e da crónica são muito parecidos entre si. É óbvio que Lobo Antunes, desde Memória de elefante, tem recorrido a uma estética da anamorfose e do grotesco que engendra um caudal de equivalências entre seres animados e inanimados. É óbvio que um vocabulário composto de termos como fusão, conexão e fluidez, centrais para o meu argumento, pode ser usado com muito sucesso para atribuir valor a uma constelação de opções formais e simbólicas típicas da narrativa antuniana. Mas o que eu proponho, como um passo argumentativo também óbvio, é que, nas mãos de Lobo Antunes, a forma excepcionalmente aberta e adaptativa da crónica produz uma forma de arte ambiental que, por sua vez, está em sincronia com a angústia ecológica que, assegura-nos Bruno Latour, é hoje transmitida em termos globais. Libertando-se do jargão esotérico de Lobo Antunes e da ideia de que o romance funciona como um meio especial para alcançarmos o domínio cognitivo da existência, o sentimento dos leitores sugere-nos justamente que a abertura à coexistência é a 
habilidade especial das crónicas, o seu encantamento silencioso. Para Lobo Antunes, a imortalidade literária ainda toma a forma de um passo adicional na história do romance. Todavia, julgo que o seu legado não vai depender de como o autor justifica para si mesmo as suas visões e crenças, mas do facto do leitor continuar a valorizar o modo como a leitura é capaz de expandir a sua experiência privada.

Como não me custa partilhar este hábito de fruição das crónicas, para concluir este ensaio vou por isso avançar, contra o autor, com uma recomendação prática. Na altura em que o romance antuniano está refém de uma lógica discursiva previsível e o seu virtuosismo técnico já não surpreende tanto o leitor como surpreende o escritor, é preciso dizer que o que sobrevive à revogação do mandato expedicionário do romance é, meramente, a crónica. Esta maneira de ver as coisas ajuda-nos a evitar a condescendência do "transmissor" dos romances em relação ao autor dos textos inferiores. Constituindo uma sátira ao género de previsões que Lobo Antunes promulga sobre o sistema do "livro," a crónica foi capaz de se libertar dos espetros de pureza do romance e parafrasear essa condescendência nos termos de uma intensificação do tempo presente. Se a considerarmos nestes termos, a crónica, em vez de um textozinho descuidado, surge-nos sob a forma de uma contra-narrativa do apocalíptico rapar do tacho que vem assombrando o romance de Lobo Antunes e, por essa via, enquanto experiência estética, surge-nos mais apta do que o romance a reorientar a nossa consciência para as trilhas do pensamento ecológico. É por esta razão que penso que a forma idiossincrática das crónicas se pode ver como equivalente da forma última e definitiva a que o romance aspira - desde que invertamos os seus termos. É ainda por essa razão que quero recomendar que se ponha cobro à ladainha abusivamente simplificadora que segue a norma de Lobo Antunes e interpreta a crónica por meio do que nas crónicas ele nos diz dos seus romances, propondo, em alternativa, que é pertinente ver o romance como um caso restrito do ecossistema expansivo dos livros de crónicas. Para dizê-lo com ousadia e sem ambiguidades: propondo mesmo que o romance seja visto como um estágio de treinamento para a situação pós-romance da crónica. Para dizê-lo em forma de uma provocação aos críticos: ao fim e ao cabo, trinta anos depois, talvez a crónica se tenha tornado a continuação de Conhecimento do inferno por outros meios. Por isso, à recomendação de Lobo Antunes de que devemos utilizar as crónicas como pontos de apoio para compreender melhor os romances, eu contraponho o 
facto de que, mesmo que os romances possam eventualmente "atingir o coração do coração e iluminar tudo"(QUILC 342), a preocupação central que os informa impede que configurem o terreno neutro a partir do qual se pode argumentar responsavelmente sobre as crónicas. Apesar de tudo, Lobo Antunes reconhece o valor das suas crónicas. Se teima em situá-las num plano subalterno, julgo que o que ele tem em mente é não desmoralizar ante a dificuldade crescente de levar adiante o seu projecto literário, simultaneamente transgressivo e teleológico, e garantir que se mantém completamente mergulhado na tarefa de esculpir as frases sóbrias e monumentais que levam o próximo livro a revelar passados sempre mais interiores e truques estilísticos sempre mais densos.

Seja como for, quero deixar claro que não estou a insinuar que devemos criticar Lobo Antunes e a devoção com que tenta abrir novos caminhos no espaço literário. Apenas quero sugerir que perguntas distintas tendem a gerar respostas distintas. Como se sabe, o tema da imortalidade literária não deixa de incluir uma modalidade de Realpolitik. E mesmo que Lobo Antunes não esteja disposto a admiti-lo, em última instância, "livro" é qualquer coisa que um leitor chama de livro. Ideal ou não, o leitor eco-consciente lê as crónicas com seriedade, sabe o que fazer com o que lê (o que nem sempre sucede com o romance) e já há muito tempo nos dá a entender, ainda que por meias palavras, que onde estava o romance há de estar a crónica.

Objectivamente, quem nos deu uma solução para o litígio que Lobo Antunes levantou quando, em nome do seu afeto pela tradição literária ocidental e a expensas de uma excêntrica auto-encenação, esvaziou a forma da crónica do seu peso pragmático e se manteve fiel ao mito organicista do romance e à sua relutância pelo tempo presente, não foi senão este eco-leitor que, cautelosamente, se tem mantido um passo atrás dele. Pode-se tomar como exemplo a seguinte passagem: "É apenas disso que necessito para começar: não ter mais nada dentro a não ser a obra e o que existe à minha volta se esbater até deixar de existir" (QUILC 17). Mesmo que uma pessoa se sinta afortunada por ler romances do calibre dos de Lobo Antunes, muitas vezes acabamos por preferir livros capazes de encetar prontamente uma conversa connosco, em vez de livros coagidos por uma fantasia privada. Penso que Lobo Antunes tem razão quando nos diz que, assim que nos desembaraçarmos dos "largos círculos concêntricos que se estreitam e aparentemente nos sufocam" (SLC 115), descobriremos que os romances podem fazer muito por nós. Mas também penso que, ao enraizar o seu 
legado na proeminência do romance, Lobo Antunes não tem em linha de conta o facto de que esse género de livro tem perdido grande parte das antigas funções. E também não tem em linha de conta o facto de que é perfeitamente razoável admitir que um leitor do antropoceno, angustiado com os relatórios sobre as mudanças climáticas, prefira ler a crónica da próxima semana, em detrimento do livro sublime do próximo ano, pura e simplesmente porque não quer viver sufocado.

\section{Obras citadas}

Arnaut, Ana Paula. Entrevistas com António Lobo Antunes, 1979-2007: confissões do trapeiro. Almedina, 2008.

Cardoso, Norberto do Vale. António Lobo Antunes: as formas mudadas. Texto, 2016.

Filipe, Celso. O que faria eu se estivesse no meu lugar? 10 conversas de vida com António Lobo Antunes. Planeta, 2016.

Fish, Stanley. Is There a Text in This Class?: The Authority of Interpretive Communities. Harvard UP, 1980.

Han, Byung-Chul. A sociedade do cansaço. Traduzido por Gilda Lopes Encarnação, Relógio D’Água, 2014.

Harrison, Robert. Forests: The Shadow of Civilization. U of Chicago P, 1992.

Lobo Antunes, António. "O meu futuro." Visão, 2 Mar. 2017, visao.sapo.pt /opiniao/opinião_antonioloboantunes/2017-03-02-O-meu-futuro.

-. Quinto livro de crónicas. Dom Quixote, 2013.

—. Segundo livro de crónicas. Dom Quixote, 2007.

—. Terceiro livro de crónicas. Dom Quixote, 2006.

Morton, Timothy. The Ecological Thought. Harvard UP, 2010.

Rorty, Richard. Contingência, ironia, solidariedade. Traduzido por Nuno Fonseca, Presença, 1994.

Seixo, Maria Alzira. As flores do inferno e jardins suspensos. Dom Quixote, 2010.

Sousa, Sérgio Guimarães de. Quem sou eu? Ensaios sobre António Lobo Antunes. Texto, 2015.

Viveiros de Castro, Eduardo. Metafísicas canibais. Ubu, 2018. 